\title{
The Influence of Pre-wetted Lightweight Aggregates' Volume Fractions on Shrinkage
}

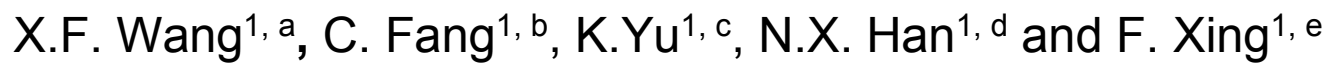 \\ ${ }^{1}$ Guangdong Key Laboratory of Durability in Coastal Civil Engineering, College of Civil Engineering, \\ Shenzhen University, Shenzhen, Guangdong 518060, China \\ axfw@szu.edu.cn, b2151150202@email.szu.edu.cn, c460250535@qq.com, dnxhan@szu.edu.cn \\ and exingf@szu.edu.cn
}

\begin{abstract}
Keywords: Lightweight aggregate concrete (LWAC); Shrinkage; Prediction model Abstract. In this study, the influence of three types of pre-wetted lightweight aggregates (PLWA) on the shrinkage of concrete was experimentally investigated, in which the variation of the volume fractions and moisture content was considered. The results show that the shrinkage of concrete after age $150 \mathrm{~d}$ increased with increasing the PLWA content, while the change was not linear. It was found that the use of PLWA increased the shrinkage at $240 \mathrm{~d}$ due to the significant increase in the shrinkage deformation during the age of $28 \mathrm{~d}$ to $90 \mathrm{~d}$, which was supposed to be caused by the internal curing.
\end{abstract}

\section{Introduction}

Shrinkage was one of the essential parameters for the design of concrete structures [1]. The change of deleterious volume in constrained condition easily causes tensile stress and may lead to the initiation and propagation of microcracks [2], which may impair the durability and compromise the performance of concrete structures. Hence, it is necessary to develop new technologies to alleviate these negative impacts caused by the shrinkage.

Pre-wetted lightweight aggregate, also known as internal curing (IC) [3-6], has been reported as an effective strategy in reducing autogenous shrinkage and preventing cracking at early age. Autogenous shrinkage and drying shrinkage are usually because the drop of moisture inside material caused by the environmental drying and the cement hydration [7]. Water stored in the pores of PLWA is available to aid in curing $[4,8,9]$, thereby negating the effects of self-desiccation and the moisture loss. Research on the internal curing has indicated that cracking potential could be effectively reduced by the dispersion of the internal water reservoirs [10].

Through many works have been done to investigate the effect of pre-wetted lightweight aggregate on the shrinkage and crack sensitivity of concrete, the effect of different pre-wetted lightweight aggregates volume fractions on shrinkage is still unknown. In this paper, experimental work considering three types of lightweight aggregates with five volume contents $(0 \%, 30 \%, 50 \%, 70 \%$, and $100 \%$ ) were conducted. Experimental results of the effect of PLWA's fraction on the long-term shrinkage were reported and discussed.

\section{Materials and mixing proportions}

Three types of lightweight aggregates adopted as IC agent in this study were commercially available, namely Nantong ceramsite ( $N$, fly ash-clay ceramsite), Yichang ceramsite (Y, shale ceramsite) and Zhengzhou ceramsite ( $\mathrm{Z}$, clay ceramsite). The water absorption rate $(24 \mathrm{~h})$ of the three kinds of ceramsite are $13.45 \%, 6.80 \%$ and $11.57 \%$, respectively. China Portland Cement PII 42.5R type and polycarboxylate-based superplasticizer were used. $486 \mathrm{~kg} / \mathrm{m} 3$ of cementitious material, $465 \mathrm{~kg} / \mathrm{m} 3$ of coarse aggregates (weight of stone), $843 \mathrm{~kg} / \mathrm{m} 3$ of fine aggregates and $7.29 \mathrm{~kg} / \mathrm{m} 3$ of polycarboxylate-based superplasticizer were used in the original groups (N2, Y2 and Z2). By partial replacing normal-weight coarse aggregates with the PLWA (by volume), mixtures (L100, L70G30, L50G50, L30G70, and G100) were obtained. All coarse aggregates were immersed in water for 24h before the test, and the absorbed water content $(24 \mathrm{~h})$ was included in the moisture content of aggregates, which was recommended by many researchers $[3,4]$. 
Table 1 Mixture designs

\begin{tabular}{lllllllll}
\hline Mix ID & $\begin{array}{l}\text { PLWA } \\
\text { content } \\
\text { (Vol. \%) }\end{array}$ & $\begin{array}{l}\text { Effective } \\
\text { w/c ratio }\end{array}$ & Mix ID & $\begin{array}{l}\text { PLWA } \\
\text { content } \\
\text { (Vol. \%) }\end{array}$ & $\begin{array}{l}\text { Effective } \\
\text { w/c ratio }\end{array}$ & Mix ID & $\begin{array}{l}\text { PLWA } \\
\text { content } \\
\text { Vol. \%) }\end{array}$ & $\begin{array}{l}\text { Effective } \\
\text { w/c ratio }\end{array}$ \\
\hline N1 (L100) & 100 & 0.26 & Y1 (L100) & 100 & 0.33 & Z1 (L100) & 100 & 0.28 \\
N2 (G100) & 0 & 0.39 & Y2 (G100) & 0 & 0.39 & Z2 (G100) & 0 & 0.39 \\
N3 (L30G70) & 30 & 0.35 & Y3 (L30G70) & 30 & 0.37 & Z3 (L30G70) & 30 & 0.36 \\
N4 (L50G50) & 50 & 0.33 & Y4 (L50G50) & 50 & 0.36 & Z4 (L50G50) & 50 & 0.34 \\
N5 (L70G30) & 70 & 0.30 & Y5 (L70G30) & 70 & 0.35 & Z5 (L70G30) & 70 & 0.31
\end{tabular}

* The letters and numbers in Mix ID indicate the volume content of PLWA and stone. For example, L30G70+means that the volume ratio of PLWA to stone is 3:7.

\section{Test method of long term shrinkage}

15 groups of mixing proportion (shown in Table 1) were test. In accordance with China National Standard (GB/T 50082-2009), contact shrinkage measuring method was adopted. The specimens with the dimensions of $100 \mathrm{~mm} \times 100 \mathrm{~mm} \times 515 \mathrm{~mm}$ were stripped after curing for $24 \mathrm{~h}$, and then mounted to the shrinkage measuring apparatus. All samples were being cured under the condition of constant temperature $\left(\mathrm{T}=(20 \pm 2){ }^{\circ} \mathrm{C}\right)$ and humidity $(\mathrm{RH}=(60 \pm 5) \%)$ to the tested ages. Copper probe was embedded in the upper part of the specimens before casting, and the shrinkage deformation was measured by micrometer with an accuracy of $1 \mu \mathrm{m}$. The deformation data was recorded in accordance with the following ages: $1 \mathrm{~d}, 2 \mathrm{~d}, 3 \mathrm{~d}, 4 \mathrm{~d}, 5 \mathrm{~d}, 6 \mathrm{~d}, 7 \mathrm{~d}, 14 \mathrm{~d}, 28 \mathrm{~d}, 45 \mathrm{~d}, 60 \mathrm{~d}, 90 \mathrm{~d}, 120 \mathrm{~d}, 150 \mathrm{~d}, 180 \mathrm{~d}, 210 \mathrm{~d}$ and $240 \mathrm{~d}$ (the age was counted from the date of stripping). Mean values of three replicate specimens were taken as the representative one and a total of 90 specimens were tested. The shrinkage was then calculated as follows,

$\varepsilon_{\mathrm{st}}=\frac{l_{0}-l_{t}}{l_{b}}$

where, $\mathcal{E}_{s t}$ denotes the shrinkage strain of concrete at time $t, l_{0}$ signifies the initial reading, $l_{t}$ means the reading at time $t$ and $l_{b}$ represents the gauge length.

\section{Effect of different PLWA volume fractions on shrinkage}

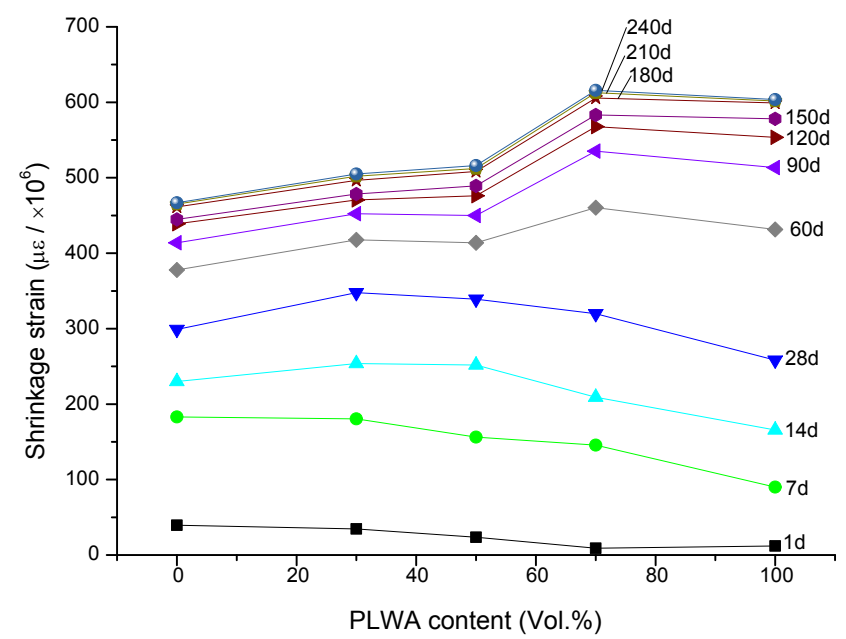

(a) Ceramsite $\mathrm{N}$

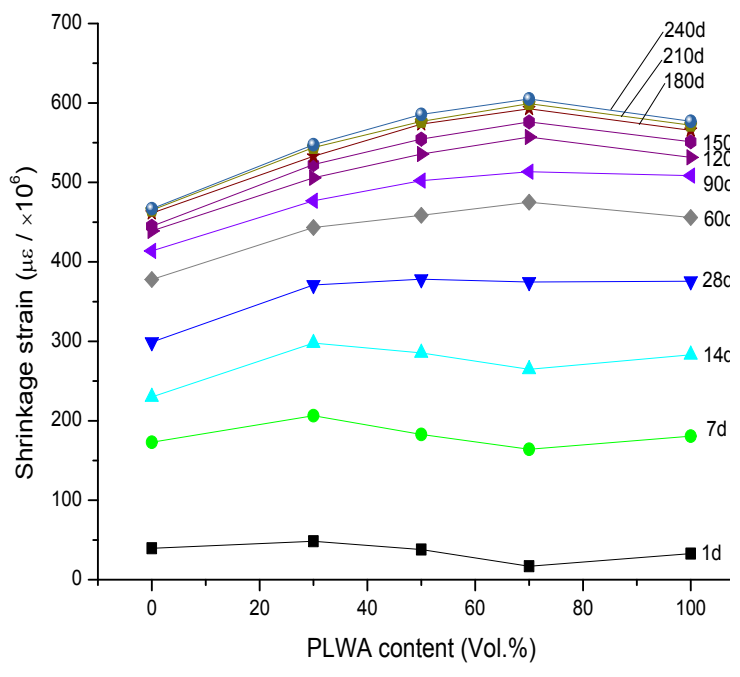

(b) Ceramsite Y 


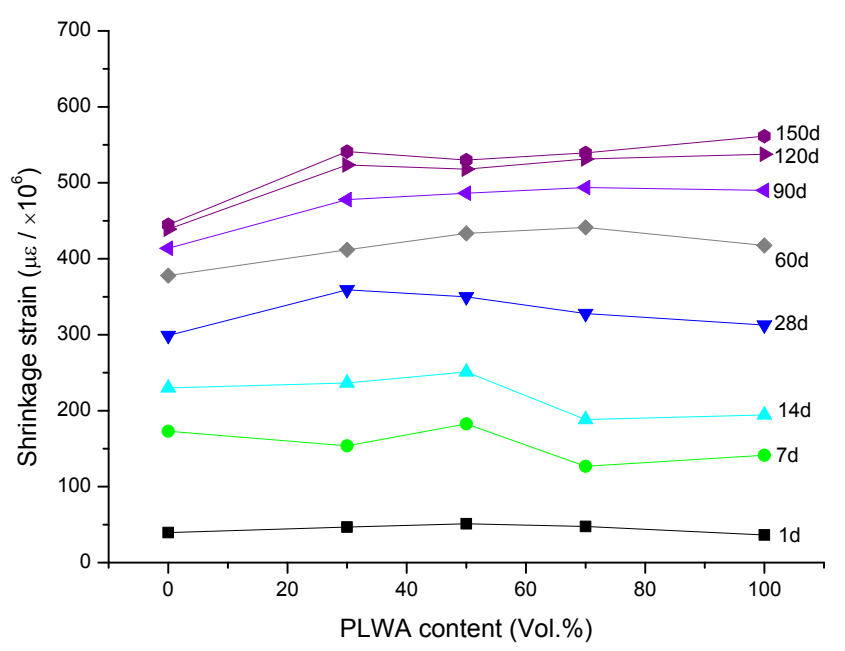

(c) Ceramsite Z

Fig. 1 The shrinkage of concrete versus PLWA's volume content

Fig. 1 plots the variation in the shrinkage strain of concrete with the volume content of PLWA. Considerable distinction in the shrinkage strain according to the types and volume fractions of aggregates can be seen. In Fig. 1 (a), the shrinkage strain of group $\mathrm{N}$ at $1 \mathrm{~d}$ and $7 \mathrm{~d}$ both show decreasing trend as the PLWA volume content increased from $0 \%$ to $30 \%, 50 \%, 70 \%$ and $100 \%$. The increase in volume of PLWA results in higher amount and better distribution of IC water, which can help reduce shrinkage at this age. But due to a lower moisture content of $Y$ and $Z$, a minimal influence of PLWA's volume content to the shrinkage strain of group $\mathrm{Y}$ and $\mathrm{Z}$ is observed at the age of $1 \mathrm{~d}$ and 7d (see Fig. 1 (b) and (c)).

Note that, the shrinkage of concrete containing PLWA during the age of $28 \mathrm{~d}$ to $90 \mathrm{~d}$ was influenced by the moisture content and volume content of lightweight aggregates. During the age of $28 \mathrm{~d}$ to $90 \mathrm{~d}$, the shrinkage increased to $104.55,110.83,215.45$ and $255.25 \mu \varepsilon$, respectively, for concrete with $30 \%$, $50 \%, 70 \%$ and $100 \%$ PLWA in group $\mathrm{N}$, in which the aggregate has the largest moisture content (13.48\%); whereas in group $\mathrm{Z}$ the shrinkage increased to $118.71,136.51,165.95$ and $177.36 \mu \varepsilon$ (the moisture content is $11.57 \%$ ); and in group $Y$ the shrinkage increased to $105.88,124.09,138.78$ and $132.92 \mu \varepsilon$ (the moisture content is $6.8 \%$ ). High drying shrinkage caused by high internal relative humidity in concrete containing PLWA $[11,12]$ should be attributed to this.

Stone has a larger stiffness than ceramsite, partial replacing stone by PLWA should increase the long-term shrinkage of concrete. As expected, the shrinkage of concrete in group N, Y and Z after 60d increased to some extent with the PLWA's content increased from $0 \%$ to $30 \%, 50 \%, 70 \%$ and $100 \%$. However, in group N and Y (see Fig. 1(a) and (b)), the shrinkage strain of concrete with 70\% PLWA after $60 \mathrm{~d}$ is larger than that of concrete with $100 \%$ PLWA. This may be caused by the incompatibility between normal-weight aggregate and lightweight aggregate.

\section{Conclusions}

Through the analysis and discussion of the experimental results, it was found that the PLWA significantly increased the shrinkage at $240 \mathrm{~d}$ due to the significant increase in the shrinkage deformation during the age of $28 \mathrm{~d}$ to $90 \mathrm{~d}$. The shrinkage during the age of $28 \mathrm{~d}$ to $90 \mathrm{~d}$ demonstrated an increasing trend as the volume content or the moisture content of PLWA increased. The increasing trend was found in the shrinkage of concrete after the age of $150 \mathrm{~d}$ by increasing the PLWA content, in which the change was not linear. 


\section{Acknowledgements}

This work was financially supported by the General Program of the National Natural Science Foundation of China (No.51478272), the joint funds of the National Natural Science Foundation and Guangdong Province of China (U1301241), the International Cooperation and Exchange of the National Natural Science Foundation of China (51520105012), the Science and Technology Foundation for the Basic Research Plan of Shenzhen City (JCYJ20160422095146121), and the Collaborative Innovation Research Centre for Environment-Friendly Materials and Structures in Civil Engineering, Southeast University.

\section{References}

[1] M.J. Oliveira, A.B. Ribeiro and F.G. Branco: Constr. Build. Mater. Vol. 52 (2014), p.267-275

[2] O.M. Jensen, in: RILEM Workshop on Shrinkage of Concrete, Paris, RILEM Publications S.A.R.L, Cachan Cedex, France (2000), p.143-153.

[3] X.F. Wang, C. Fang, W.Q. Kuang, D.W. Li, N.X. Han and F. Xing: Constr. Build. Mater. Vol.136 (2017), p.173-183.

[4] R. Henkensiefken, D. Bentz, T. Nantung and J. Weiss: Cem. Concr. Compos. Vol.31 (2009), p.427-437.

[5] S. Zhutovsky, K. Kovler and A. Bentur: Mater. Struct. Vol.35, (2002), p.97-101.

[6] D.P. Bentz and W.J. Weiss, in: National Institute of Standards and Technology Interagency Report (2011).

[7] J. Zhang, Q. Wang and J. Zhang: Constr. Build. Mater. Vol.134 (2017), p.664-672.

[8] R. Henkensiefken, J. Castr, D. Bentz and T. Nantung, J. Weiss: Cem. Concr. Res. Vol.39 (2009), p.883-892.

[9] K.S. Youm, J. Moon, J.Y. Cho and J.J. Kim: Constr. Build. Mater. Vol.114 (2016), p.517-527.

[10] R. Henkensiefken, G. Sant, T. Nantung and J. Weiss, in: ACI Spring Convention, San Antonio, TX (2009), p.77-88

[11] A.M. Neville, Properties of Concrete, fourth ed., Prentice Halls, HK (2000).

[12] K. Kohno, T. Okamoto and Y. Isikawa: Cem. Concr. Res. Vol.29 (1999), p.611-614. 